\title{
Болгаро-российские взаимодействия в архитектуре Болгарии в начале XX века: нео-византийская стилистика и национальный романтизм
}

\author{
Атанас Ковачев, Лесотехнический университет, София \\ Стела Ташева, Лесотехнический университет, София
}

В статье авторы сосредотачиваются на нескольких объектах, решённых в нео-византийской стилистике, построенных в Болгарии болгарскими и русскими архитекторами, и прослеживают взаимодействие их проектных идей.

Ключевые слова: архитектура Болгарии, нео-византийская стилистика, национальный романтизм, культовые постройки, российские и болгарские архитекторы.

Bulgarian-Russian Interactions in the Architecture of Bulgaria at the Beginning of the Twentieth Century: NeoByzantine Stylistics and National Romanticism. Atanas Kovachev, Stela Tasheva

Atanas Kovachev, University of Forestry, Sofia

Stela Tasheva, University of Forestry, Sofia

In the article, the authors focus on several objects designed in neo-Byzantine style, built in Bulgaria by Bulgarian and Russian architects, and trace the interaction of their design ideas.

Keywords: Bulgarian architecture, neo-Byzantine stylistics, national romanticism, religious buildings, Russian and Bulgarian architects.

Согласно определениям, нео-византийская стилистика (также известная как Византийское Возрождение) - это направление в архитектуре, которое распространилась по всей
Европе и Северной Америке во второй половине XIX и первой половине XX веков, оно опирается на эстетику архитектурного наследия Византии [1]. Был создан целый ряд архитектурных объектов, в том числе некоторые промышленные здания, такие как «Уэйт и Джеймс Грейри» (Wate and James Graary, 1869) и склад Робинсон (Robinson, 1874) в Бристоле [2] (рис. 1 a). Знаменитыми культовыми зданиями этого стилистического направления являются Владимирский собор в Киеве (1862), собор св. Франциска Сальского в Филадельфии (Пенсильвания, 1890), собор св. Софии в Лондоне (1891) (рис. 1 б), Вестминстерский собор в Лондоне (1903), собор Архангела Михаила в Каунасе (1895) (рис. 1 в), Морской Никольский собор в Кронштадте (1903-1912) и многие другие.

Исследование культовых построек началось ещё с наследия Древней Греции, а затем Древнего Рима. Постепенный рост интереса к наследию средневековой Византии в конце XIX - начале XX века стал важным фактором, способствовавшим поиску новых архитектурных интерпретаций в храмовом зодчестве.

Византийское Возрождение и по времени, и по своей концепции ближе к нео-готической архитектуре. Наличие произведений подлинной готической стилистики отличает многие европейские регионы, поэтому возрождение этих традиций подразумевало обращённость архитектуры к национальным или локальным вариантам традиций.

Нео-византика получила развитие в разных масштабах: территориальных и объектных, заняв своё место в бурном эклектическом расцвете конца XIX - начала XX века. В архи-

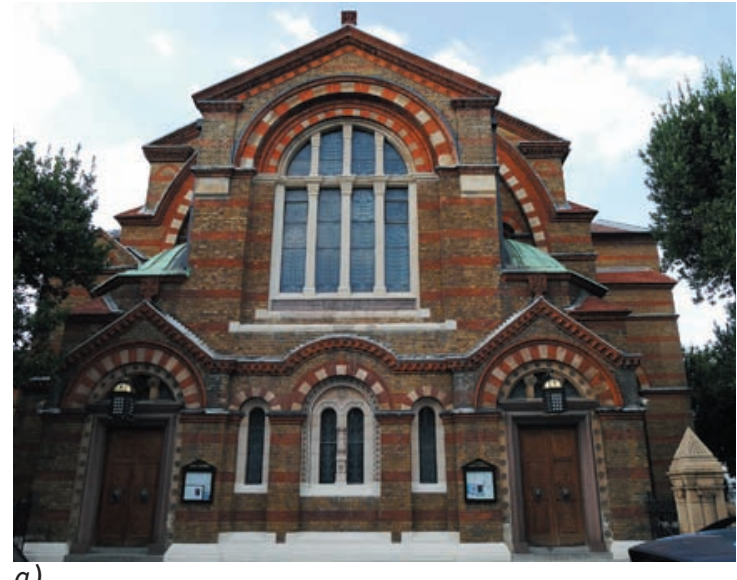

a)

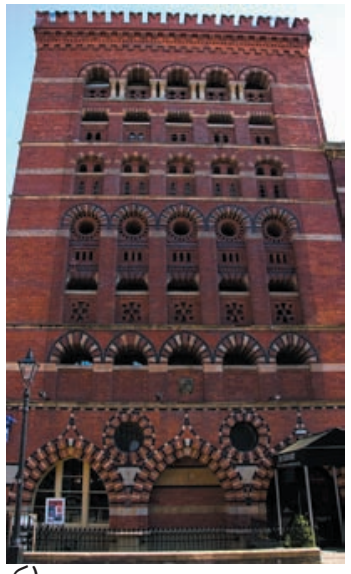

б)

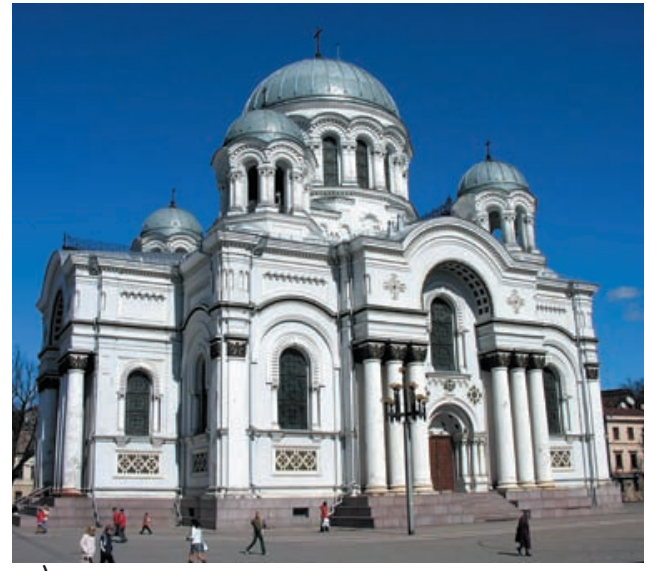

B)

Puc. 1. Примеры зданий в нео-византийской стилистике: а) Бристольский амбар (источник: https://upload.wikimedia.org/ wikipedia/commons/0/00/Uk_bristol_granary.jpg); б) православная греческая церковь св. Софии в Лондоне (источник: http:// forum.arimoya.info/attachments/1879-st_sophias_cathedral-_london_04-jpg.58399/); кафедральный собор Архангела Михаила в Каунасе (источник: https://www.asienda.ru/data/cache/2017aug/09/27/709630_12045.jpg) 


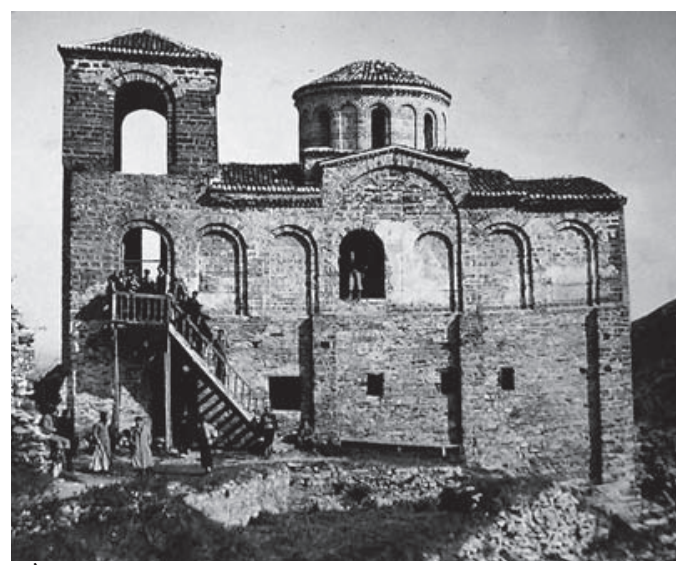

a)

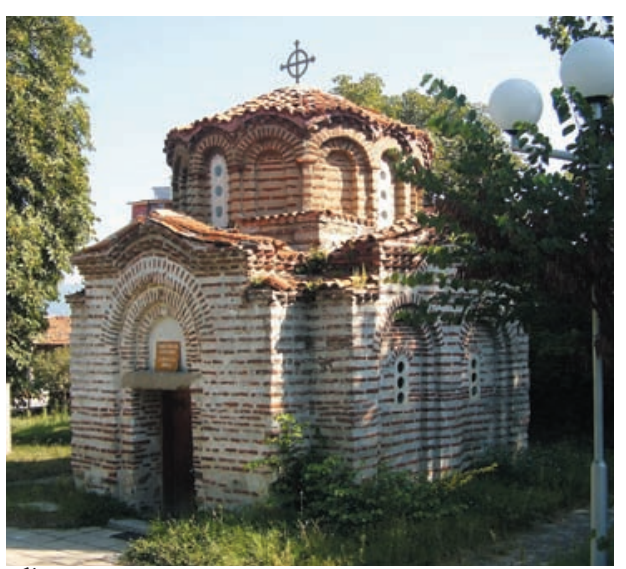

б)

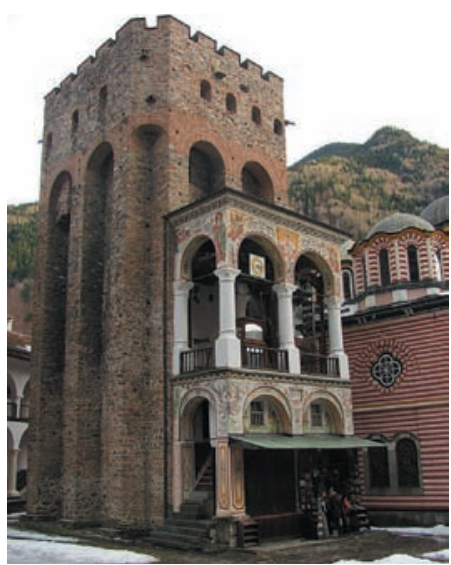

B)

Puc. 2. Примеры сохранившихся и изученных памятников XII-XV веков в Болгарии: а) церковь Пресвятой Богородицы Петрич в крепости Ассен. Фото начала XX века (источник: https://upload.wikimedia.org/wikipedia/commons/b/bc/Asenova-krepost01.jpg); б) церковь св. Николая в Сапаревой Бане (источник: http://perego-shop.ru/gallery/images/831250_sapareva-banya.jpg); в) Хрелева башня в Рыльском монастыре (источник: https://im3.turbina.ru/photos.4/8/4/4/9/8/1789448/big.photo/Rilskiy-monastyr-yarko.jpg)
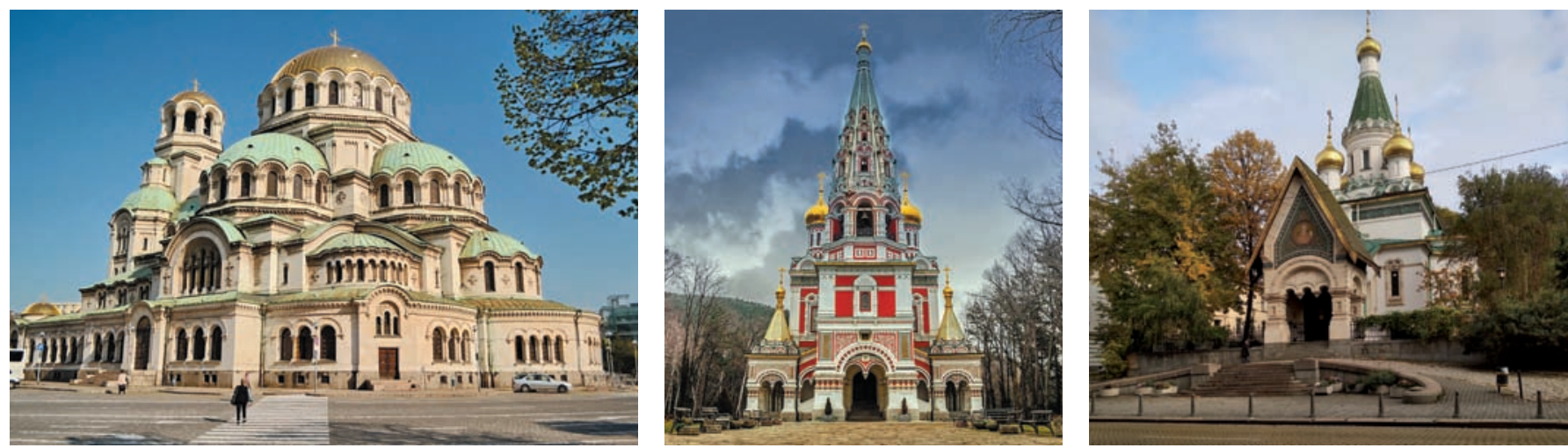

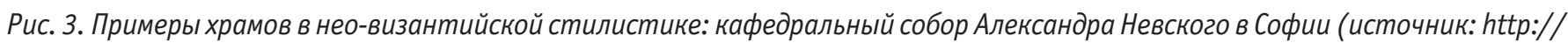
two-hitchhikers.ru/wp-content/uploads/2014/04/1-3.jpg); Шипкинский мемориальный храм (источник: https://complexlazur. com/wp-content/uploads/2016/06/\%D0\%BF\%DO\%BO\%DO\%BC\%DO\%B5\%D1\%82\%DO\%BD\%DO\%B8\%DO\%BA.jpg); Русская церковь святителя Николая Чудотвориа в Софии (источник: https://www.vrichane.bg/files/1522846688222078.jpg)

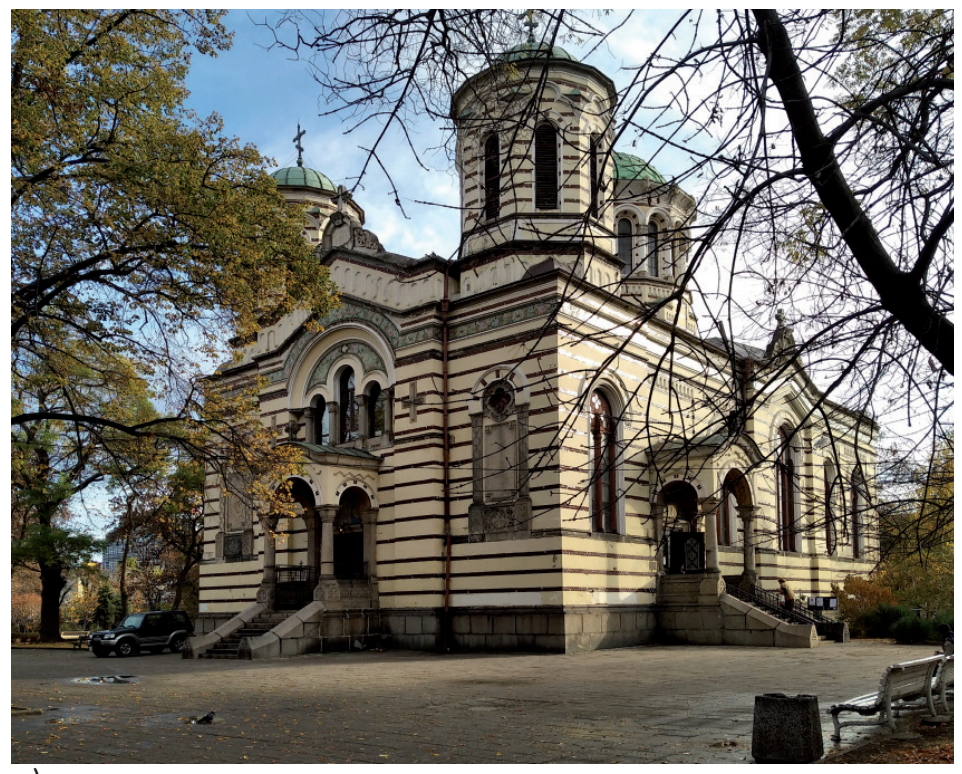

a)

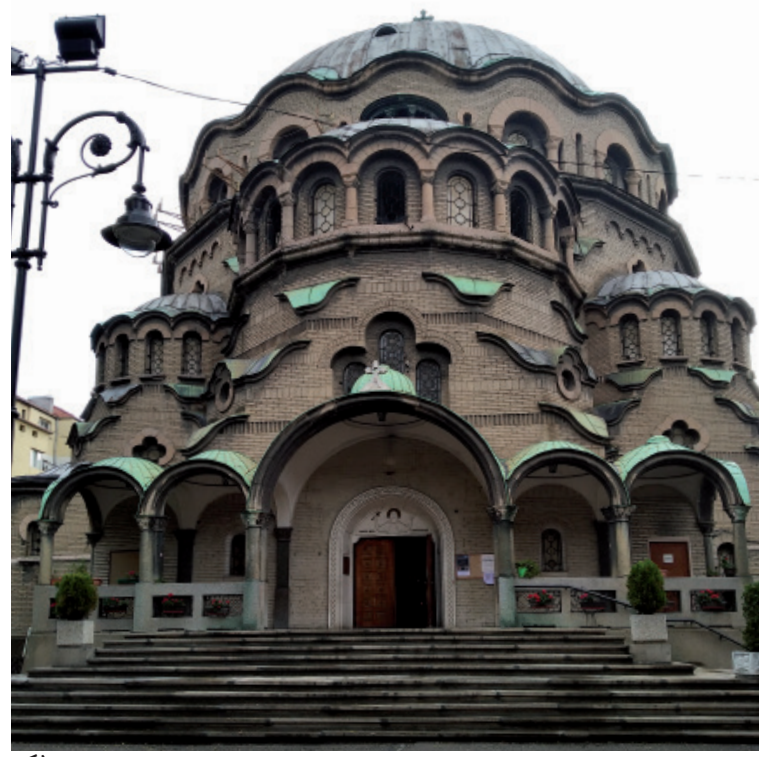

б)

Рис. 4. Региональная специфика в культовых сооружениях: а) церковь св. Николая Софийского. Архитектор Антон Торнев. 1900 год; б) черковь св.мученицы Параскевы. Архитектор Антон Торнев. 1930 год. Фото из личного архива А. Ковачева 
тектурных решениях зданий появилось много стилистических комбинаций, признаков неоготики, нео-византийского, мавританского стиля, украшений и элементов ренессанса, барокко, модерна, сецессиона и других.

Географическая специфика балканского региона, и в частности Болгарии, - в непосредственной близости к территории Византии, а в отдельные периоды - даже вхождение территории в саму империи. Обе страны - Болгария и Византия - идентичны как по православному вероисповеданию, так и по строительным традициям и технологиям. В качестве общеизвестных, в той или иной степени сохранившихся и изученных памятников XII-XV веков в Болгарии можно упомянуть церкви прсв. Богородицы Петрич в крепости Ассена (рис. 2 а) и св. Николая в Сапаревой Бане
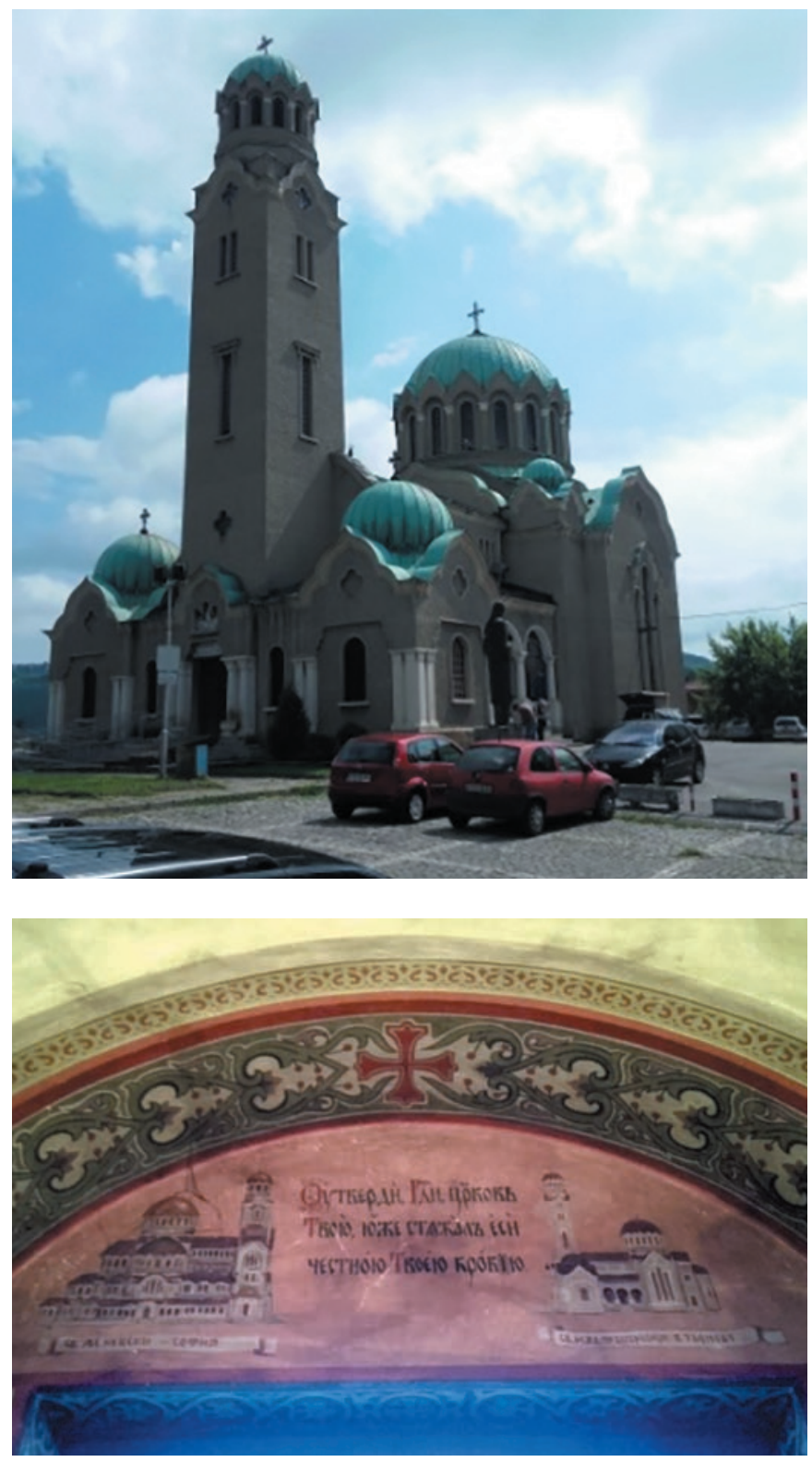

Рис. 5. Храм Рождества Пресвятой Богородицы в Велико Тырново; б) фрагмент росписи стен храма. Фото из личного архива А. Ковачева (рис. 2 б), Несебрские храмы, такие как Христа Пантократора и св. Параскевы [3], Хрелеву башню в Рильском монастыре (рис. 2 в). 0блик этих построек вдохновляет архитекторов на использование «национально-романтического» стиля и на архитектурные интерпретации образов Болгарского средневековья.

Таким образом, в начале XX века в Болгарии византийская стилистика была интерпретирована как составляющая двух различных концепций: как своего рода ответ на мировые архитектурные тенденции - применение нео-византийского стиля, и как собственный опыт создания национального стиля.

Пожалуй, самым известным образцом нео-византийской стилистики на территории Болгарии является православный собор св. Александра Невского (рис. 3 а). Главный камень храма был заложен на месте будущего здания 19 февраля 1882 года. Строительство церкви продолжалось в течение двух десятилетий, а освящён храм был в 1924 году. Первоначально было поручено «русскому архитектору Богомолову подготовить необходимые эскизы и спроектировать храм», - писал Пенчо Койчев [4], но из-за событий в 1885 году в Болгарии (заключение Союза Болгарии с Восточной Румелией и последующая сербо-болгарская война) строительство затянулось, и в 1896 году «для рассмотрения и пересмотра проекта Богомолова» был приглашён А.Н. Померанцев ${ }^{1}$, - писал Койчев. Поскольку объём здания значительно увеличился, «было предложено использовать формы других древних памятников в Болгарии». «0бщий стиль храма - восточно-православный, и представляет собой сочетание византийско-русско-болгарских мотивов», - пишет Трайчев [5]. В соборе можно разместить около 5000 молящихся.

Конечно, выбор (нео)византийской стилистики не был единственно возможным как для православной церковной архитектуры того времени как в целом, так и для творчества русских архитекторов, строивших в Болгарии. Например, стилистика Шипкинского мемориального храма (рис. 3 б), со строительством которого связаны имена нескольких русских архитекторов (А. О. Томишко, Р. Р. Марфельд, А.Н. Померанцев, А.Н. Смирнов, А.Ю. Ян), сообщает Маргарита Коева [6], «полностью укоренена в стиле "русской старины", столь популярном в России в 80-х годах XIX века». Ситуация с Русской церковью святителя Николая Чудотворца в Софии (рис. 3 в) аналогична. Проект этого храма был разработан Михаилом Преображенским, а строительством, завершённым в 1911 году, руководил А.Н. Смирнов. Для этого храма был избран стиль «московской церковной архитектуры семнадцатого века». Сейчас этот храм является подворьем Патриарха Московского и Всея Руси в Софии [7].

Архитектору А.Н. Смирнову София также обязана постройкой здания Национальной академии искусств («Школы

${ }^{1}$ «А.Н. Померанцев с 1892 г. профессор, затем действительный член СанктПетербургской Императорской академии художеств. Померанцев - типичный представитель эклектики последней фазы её развития» [Кириченко Е.И. А. Померанцев (1848-1918) // Зодчие Москвы. - М. : Московский рабочий, 1981, С. 261]. 
рисования») (1907). Внешний вид здания оценивается как «нюансное сочетание византийского стиля с элементами русской традиционной архитектуры» [8, с. 71].

Стилистические поиски болгарских, а также работающих в Болгарии русских и европейских архитекторов, достигли своего пика в таких известных зданиях, как синагога, минеральные бани и Теологическая (Духовная) академия. Эти постройки становятся своего рода отправной точкой для последующих стилистических поисков.

«Прямой контакт между русскими и болгарскими архитектурными школами охватывает период 1878-1920 гг., но не проходит гладко и равномерно» [6]. Наличие связей между ними сохраняется и впоследствии (хотя и в меньшей степени), особенно в облике культовых зданий. Таким образом, параллельно с неоклассическими, модернистскими и конструктивистскими влияниями - плодами глобального архитектурного развития - в этих сооружениях всё же проявляется ряд региональных особенностей.

С этой точки зрения остановимся на храме св.мученицы Параскевы в Софии и соборе Рождества Богородицы в Велико Тырново.

Задуманная и осуществлённая в 1910-е годы, церковь святой мученицы Параскевы была освящена только в 1930 году. Это не первый храм, построенный по проекту архитектора Антона Торнёва в Софии. Также очень характерна для этого периода церковь св. Николая Софийского, построенная в 1900 году: её внешний вид соответствует традиционной нео-византийской стилистике, а по композиции плана она относится к базиликальному типу.

Стимметричная планировочная схема, эффектная комбинация куполов и арок, ритмичные вариации арочных проёмов фасадов, сдержанное колористическое решение, а также встраивание колокольни в общий объём, выполненное в виде полуцилиндра, прикреплённого к основной конструкции и постепенно переходящего в куполообразную форму [9] - всё это является характерными чертами, определяющими силуэт храма.

На проект явно повлияла архитектура храма-памятника св. Александра Невского в Софии (архитекторы Иван Богомолов и Александр Померанцев). В то же время о решении церкви Св. Параскевы сам Торнёв пишет: «С точки зрения стиля проектировщик постарался придать храму национальный характер, используя... изогнутую линию, которая, по его мнению, является отличительной чертой нашего монументального сооружения».

Церковь Рождества Пресвятой Богородицы в Велико-Тырново (рис. 5 а) была завершена и освящена в 1934 году. Она построена на месте храма, датируемого серединой XIX века, автором которого был блестящий болгарский архитектор Уста Коло Фичето. Однако его здание было разрушено землетрясением 1913 года. Считается, что автор нового здания, «дед Гроше», строит здание в соответствии с данными о старых фасадах. Но, когда мы смотрим на выбор и разработку дета- лей в решениях куполов, а также на отделку стен, то можем отметить наличие некоторого «обновления» архитектурной концепции.

$\star * *$

Таким образом, прежде всего необходимо отметить влияние мемориального храма-памятника св. Александра Невского на эволюцию болгарской культовой архитектуры. На сегодняшний день это сооружение остаётся не только крупнейшим православным храмом на Балканском полуострове, но и своего рода признанным стандартом высокого качества, масштабности и значимости объекта. В то же время удачный симбиоз архитектурных стилей с региональными архитектурными традициями проявился в решениях культовых объектов начала XX века именно благодаря заимствованиям элементов русской православной архитектуры.

\section{Лumepamypa}

1. Neo-Byzantine [Электронный ресурс] // Oxford reference 2019. - Режим доступа: https://www.oxfordreference.com/ view/10.1093/oi/authority.20110803100228165 (дата обращения 18.10.2019).

2. The Granary And Attached Area Walls [Электронный ресурс] // Historic England 2019, List Entry, 2019. - Режим доступа: https://historicengland.org.uk/listing/the-list/ list-entry/1202674 (дата обращения 05.10.2019); Robinson's Warehouse [Электронный ресурс] // Historic England 2019, List Entry, 2019. - Режим доступа: https://historicengland. org.uk/listing/the-list/list-entry/1204025 (дата обращения 05.10.2019).

3. Рашенов, А. Месемврийски църкви / А. Рашенов. - София : Държавна печатница, 1932.

4. Койчев, П. Църквата Св. Александър Невски в София / П. Койчев // БИАД. - 1905. - № 11-12. - С. 139-144.

5. Трайчев, Г. Ставропигиален храм паметник Св. «Александър Невски» / Г. Трайчев. - София : Св. синод на бълг. Църква, 1923.

6. Коева, М. Руски архитекти, работили в България през периода 1879-1912 година [Электронный ресурс] // Архитектурното наследство и съвременният свят. - Варна : Електронно издателство LiterNet - 25.12.2003. - Режим доступа: https://liternet.bg/publish9/mkoeva/nasledstvo/content.htm (дата обращения 16.10.2019).

7. Храм свт. Николая Мирликийского [Электронный ресурс]. - Режим доступа: http://podvorie-sofia.bg/o-hrame2/o-hrame/sozdanie-hrama/ (дата обращения 24.10.2019).

8. България - 1900: Европейски влияния в българското градоустройство, архитектура, паркове и градини 1878-1918 / Х. Ганчев, Г. Дойчинов, И. Стоянова, Т. Кръстев - София : Арх и Арт, Проф. Марин Дринов, 2002.

9. Торньов, А. Новопостроеният храм Св. Мъченица Параскева // Архитект, ДБА. - 1930. -№ 3-4. - С. 7-15. 


\section{References}

1. Neo-Byzantine [Электронный ресурс].0xford reference 2019. URL: https://www.oxfordreference.com/view/10.1093/oi/ authority.20110803100228165 (accessed 18.10.2019). (In Engl.)

2. The Granary And Attached Area Walls. Historic England 2019, List Entry, 2019. URL: https://historicengland.org.uk/ listing/the-list/list-entry/1202674 (accessed 05.10.2019) (In Engl.); Robinson's Warehouse. Historic England 2019, List Entry, 2019. URL: https://historicengland.org.uk/listing/the-list/ list-entry/1204025 (accessed 05.10.2019) (In Engl.).

3. Rashenov A. Mesemvriiski ts"rkvi [Mesemvri churches]. Sofiya, D"rzhavna pechatnitsa Publ, 1932. (In Bulg.)

4. Koichev, P. Ts"rkvata Sv. Aleksand"r Nevski v Sofiya [The Church of St. Alexander Nevski in Sofia]. BIAD, 1905, no. 11-12, pp. 139-144. (In Bulg.)

5. Traichev, G. Stavropigialen khram pametnik Sv. "Aleksandr Nevski" [Stavropigial temple monument of St. "Alexander Nevsky"]. Sofiya, Sv. sinod na b"lg. Ts"rkva Publ., 1923. (In Bulg.)
6. Koeva, M. Ruski arkhitekti, rabotili v B"lgariya prez perioda 1879-1912 godina [Russian architects who worked in Bulgaria during the period 1879-1912]. Arkhitekturnoto nasledstvo $i$ s"vremenniyat svyat [Architectural Heritage and the Modern World]. Varna, Elektronno izdatelstvo LiterNet publ., 12-252003. URL: https://liternet.bg/publish9/mkoeva/nasledstvo/ content.htm (accessed 16.10.2019). (In Bulg.)

7. Khram svt. Nikolaya Mirlikiiskogo [Church of St. Nicholas of Myra]. URL: http://podvorie-sofia.bg/o-hrame-2/o-hrame/ sozdanie-hrama/ (accessed 24.10.2019). (In Russ.)

8. Ganchev Kh., Doichinov G., Stoyanova I., Kr"stev T. B"lgariya - 1900: Evropeiski vliyaniya v b"lgarskoto gradoustroistvo, arkhitektura, parkove i gradini 1878-1918 [Bulgaria - 1900: European Influences in the Bulgarian Urban Planning, Architecture, Parks and Gardens 1878-1918]. Sofiya; Arkh i Art, Prof. Marin Drinov Pudl., 2002. (In Bulg.)

9. Torn'ov, A. Novopostroeniyat khram Sv. M"chenitsa Paraskeva [The newly built church of St. Martyr Paraskeva]. Arkhitekt, DBA, 1930, no. № 3-4, pp. 7-15. (In Bulg.)

Ковачев Атанас Димитров (София-Варна, Болгария). Член-корреспондент Болгарской академии наук, доктор архитектуры, профессор градостроительства, иностранный член РААСН. Директор Института интегрированного управления муниципалитетов Варненского свободного университета им. Черноризца Храбра, декан архитектурного факультета и руководитель кафедры «Архитектура и урбанистика» Варненского свободного университета им. Черноризца Храбра, руководитель департамента «Инфраструктурные проекты» Лесотехнического университета (София), руководитель архитектурной мастерской «Ковачев архитекти - ЕООД». Эл.почта: atanas_kovachev@mail.bg.

Ташева Стела (София). Кандидат архитектуры, доцент. Институт искусствознания Болгарской академии наук, Лесотехнический университет (София).

Kovachev Atanas Dimitrov (Sofia-Varna, Bulgaria). Corresponding Member of the Bulgarian Academy of Sciences, Doctor of Architecture, Professor of Urban Planning, Foreign Member of RAACS. Director of the Institute for Integrated Management of the Municipalities at the Varna Free University "Chernorizets Hrabar", Dean of the Faculty of Architecture and Head of the Department of Architecture and Urban Studies at the Varna Free University "Chernorizets Hrabar", Head of the Department of Infrastructure Projects of the University of Forestry (Sofia), Head of the Architectural Studio Kovachev Architects - E00D. Email: atanas_kovachev@mail.bg.

Tasheva Stela (Sofia). Candidate of Architecture, Associate Professor. Institute of Art Studies of the Bulgarian Academy of Sciences, University of Forestry (Sofia). 